\title{
A ARMADILHA DA TÉCNICA: ENTRE PENSAR E OBEDECER
}

\author{
Leidiane Coimbra'
}

RESUMO: A instalação burocrática que caracteriza as estruturas sociais definindo as relações humanas na contemporaneidade põe em risco a liberdade do homem em decidir sobre a sua vida e a sua existência, na medida em que não tem autonomia para agir livremente apartado das interferências exteriores. A esse nível de existência se interpõem questões que se referem ao modo como a época se apresenta, qual seja, tecnológica. Para alguns, a técnica é sinal de progresso e de organização da vida, sobretudo, quando como sinal dela é possível um autogerenciamento da rotina e das relações interpessoais. No entanto, à composição da técnica pertence uma ordenação do mundo, em que este e os homens tornam-se, em referência a ela, meros disponíveis. Sendo assim, o homem disponível à técnica é o que obedece ao gerenciamento proposto por ela, seja nas estruturas sociais a que pertence, seja de modo tão íntimo a determinar o modo como ele pensa e age. A técnica atua com dispositivos de controle, antecipação e rigor que determinam previamente o modo como tudo se dispõe. Nesse sentido, a atuação do homem contemporâneo fica restrita à obediência dessa dinâmica e seu pensamento atua a partir do que é disposto para ele pela técnica. Como esta atua através de cálculos e determinações prévias, o tipo de pensamento que obedece à sua dinâmica é o que calcula. O pensamento que calcula, no entanto, funciona a partir do que é dado, do que está à mão, sem abrir espaço para a surpresa. Ao contrário dele, o pensamento que medita atém-se ao mistério presente na surpresa e na novidade, acolhendo-os como morada e nele encontrando serenidade para se relacionar com o mundo 
e com os outros homens, abrindo-se para o desconhecido que neles existe.

PALAVRAS-CHAVE: Pensamento; Obediência; Técnica, Serenidade.

ABSTRACT: The bureaucratic installation that characterizes social structures defining human relations in contemporary times puts at risk the freedom of man to decide on his life and his existence, since he does not have the autonomy to act freely from outside interference. At this level of existence questions arise that refer to the way the epoch presents itself, that is, technological. For some, technique is a sign of progress and life organization, especially when, as a sign of it, self-management of routine and interpersonal relationships is possible. However, to the composition of the technique belongs a world order, in which world and men become, in reference to technique, merely available. Therefore, the man available to the technique is what obeys the management proposed by it, either in the social structures to which he belongs, or so intimately to determine the way in which he thinks and acts. The technique works with control devices, anticipation and rigor that determine in advance the way everything is made available. In this sense, the performance of contemporary man is restricted to the obedience of this dynamics and his thinking acts according to what is arranged for him by technique. As it acts through calculations and prior determinations, the kind of thinking that obeys its dynamics is that which is calculated. The thinking that calculates, however, works from what is given, from what is at hand, without making room for surprise. Contrary to this, the thought that meditates is attached to the mystery present in surprise and novelty, welcoming them as an abode and finding in it the serenity to relate to the world and other men, opening to the unknown that exists in them.

KEYWORDS: Thinking; Obedience; Technique; Serenity. 
Estamos tão habituados às velhas oposições entre a razão e a paixão, entre o espírito e a vida, que a ideia de um pensar apaixonado, onde o Pensar e o Estar-Vivo se tornam um, espanta-nos um pouco.

Hannah Arendt

O livro Eichmann em Jerusalém - um relato sobre a banalidade do mal é originalmente escrito por Hannah Arendt como cobertura do processo de Adolf Eichmann, em 1961, para a revista The New Yorker. Eichmann havia sido preso em 1961, nos subúrbios de Buenos Aires, e levado a julgamento em Jerusalém por crimes cometidos durante o nazismo. Durante o processo a figura do "monstro" vai sendo gradativamente diluída dando lugar ao homem comum. Para o espanto de todos os presentes, Eichmann protegia-se atrás dos clichês que justificavam sua conduta como de um homem cumpridor das leis. Sendo um cidadão que cumpre ordens, que obedece às leis, Eichmann era um funcionário padrão, que não pensa por si próprio, nem se coloca no lugar do outro ao realizar suas funções. Apenas obedece a armação burocrática à qual faz parte. Alguém que obedece às funções e demandas de outrem, alguém irresponsável por seus atos. A existência de alguém que não responde por si, causa-nos um incômodo que faz surgir uma questão fundamental acerca do pensamento, qual seja, quem obedece pensa? Pode um funcionário entregar-se ao exercício do pensar? O que quer dizer, em última instância, pensar? O objetivo deste trabalho é traçar uma reflexão que possibilite uma direção a estas questões na esteira do pensamento de Arendt e Heidegger. 
Em Eichmann em Jerusalém, é comum ver Arendt se referir ao réu com adjetivos que lhe denunciavam a dificuldade ou ausência do pensar. Neste sentido, afirmou a respeito dele ser alguém com "dotes mentais bastante modestos", alguém de quem raramente se podia esperar que agisse por "conta própria", "ele não só obedecia as ordens, ele obedecia a lei"(ARENDT,1999,P.152). Agir por conta própria, ser responsável, eis o exercício, a busca individual que impulsiona o pensamento a sair da esfera mítica, como na jornada do herói em que a busca pela autonomia diante do destino liberta o homem dos desígnios dos deuses, que impulsiona o retorno de Ulisses a Ítaca, que leva o homem à autonomia de pensamento. Esse esforço, bem sabemos, é um esforço do próprio pensamento em busca de autonomia e liberdade de pensar. Se considerarmos a fórmula heideggeriana em que "o pensamento é a mais alta forma de ação"(HEIDEGGER,1984,p.149) podemos admitir que a "ausência de pensamento" conduz à obediência cega e irrefletida porque aí não acontece a atividade de pensar, o que, segundo Arendt, constitui um bios, um modo de vida. Sendo o funcionário um obediente, falta-lhe liberdade, autonomia de pensamento e ação.

Numa época em que um tipo de armação técnica (Gestell) parece orientar a disposição das coisas no mundo e o modo como nos relacionamos, as questões acerca de autonomia e liberdade não soam como um ideal, mas como um status ontológico. Segundo André Duarte,

A elevação da liberdade e da autonomia ao estatuto ontológico de princípios definidores da humanidade do 
homem é concomitante com a compreensão histórica própria do Iluminismo, segundo a qual vivemos em um tempo novo, distinto das eras passadas [...] com base na igualdade cristã de todos os homens, liberdade e autonomia foram sendo gradativamente assumidas como o verdadeiro estatuto ontológico da humanidade(DUARTE, 2010. p.107).

O entrelaçamento entre liberdade e autonomia acontece a partir do século XVIII. Antes, por exemplo, no século $\mathrm{V}$, podia-se fazer uma distinção que inscrevia a liberdade na esfera pública e a autonomia na esfera privada. Neste sentido, enquanto no Oriente antigo, apenas o déspota era livre, na res pública e na pólis grega, apenas alguns eram livres, os cidadãos. Portanto, a partir desse entrelaçamento, a liberdade é o nome para a "autonomia da vontade individual para determinar racionalmente a ação e o pensamento do sujeito"(DUARTE,2010. p.107). Duarte afirmará, na esteira da narrativa iluminista, que "ser moderno significa não apenas reconhecer a universalidade dos ideais de autonomia e liberdade, mas também relacionar e identificar a própria humanidade do homem a eles"(DUARTE, 2010. p. 108).

Parece-nos, entretanto, que diante da armação (gestell) que fundamenta a contemporaneidade em diversos âmbitos de manifestação de ser, a liberdade torna-se algo cada vez mais distante do homem proveniente dessa configuração de mundo. Segundo a tradução de Emmanuel Carneiro Leão, gestell é com-posição. Em alemão a palavra faz referência a um tipo de armação ou instalação, um tipo de equipamento, segundo Heidegger, como uma estante de livros ou o esqueleto. 
De um modo ou de outro é a palavra utilizada por ele, para definir o que seria a essência da técnica moderna. "Composição, 'Gestell', significa a força de reunião daquele pôr que põe, ou seja, que desafia o homem a des-encobrir o real no modo da dis-posição, como dis-ponibilidade"(HEIDEGGER, 2001. p.25).

Disponibilidade é um existencial, ou seja, um modo a partir do qual o homem se relaciona com o mundo, tal como o humor. Estamos no mundo, de fato, e nos relacionamos com ele sempre a partir de um humor, seja o tédio, o pavor, o horror. Nunca estamos sem humor. Este funciona como uma afinação com o mundo. Estar afinado com o mundo é sinal de que este nos toca e nos define estruturalmente. Como a afinação que permite ao instrumentista relacionar instrumento, partitura, harmonia... canção. Segue-se que o mundo nos constitui fundamentalmente, pois, é a partir dessa afinação com ele que podemos realizar modos de ser. Obviamente, a palavra mundo não faz referência a um lugar espacialmente determinado como o planeta Terra, um lugar geográfico. Aproximando-se mais de uma significação fundamental da estrutura do homem, ou seja, aquilo que nos possibilita uma realização, mundo é o horizonte de possibilidades onde o homem pode, a partir de uma relação, de uma afinação, realizar possibilidades existenciais. Ainda que saia do planeta Terra, o homem continuará no mundo. Sem mundo o homem não é, ao passo que sem homem o mundo não tem significado. Esse entrelaçamento de ambos possibilita-lhes acontecerem como tais. 
A disposição põe o mundo e os homens na perspectiva da dis-ponibilidade, do disponível. Este, por sua vez, é tudo que permite um uso, uma função, que atende a uma demanda. Aqui a dicotomia instaurada pela relação sujeito-objeto é reaplicada e ressignificada a partir do ponto de vista da disponibilidade e da exploração.

O verbo "pôr" (stellen), inscrito no termo composição, "Gestell", não indica apenas a exploração. Deve também fazer ressoar o eco de outro "pôr" de onde ele provém, a saber, daquele pro-por e ex-por que, no sentido da poiesis, faz o real vigente emergir para o desencobrimento(HEIDEGGER, 2001. p.24).

Quando Heidegger resgata o sentido de poiesis presente na composição para referir-se ao desencobrimento, ele o faz na tentativa de demonstrar que a técnica moderna é um modo de desvelamento de ser e, como tal, está no horizonte de destino do homem e, dessa maneira, uma significação instrumental ou antropológica à pergunta pela sua essência não é suficiente para demonstrar o que ela é, tampouco, o seu alcance. Se a técnica é um modo de ser que se apresenta ao destino do homem, este corresponde a ela no modo do técnico, ou melhor, do funcionário da técnica, aquele que atende à sua demanda de realização. Pois a técnica nivela homem, mundo e todos os entes na perspectiva do disponivel. Atender à demanda da técnica parece ser a característica que mais se adéqua à sua dinâmica de realização. Uma vez que 
ela dispõe do mundo, dos homens para um uso, faz parte desse jogo a encomenda, a determinação prévia, ou seja, a antecipação. Antecipar um modo de ser no horizonte da técnica é corresponder ao seu desvelamento como resultado, sendo assim, o homem significa mundo e a si mesmo dentro dessa instalação previamente preparada por ela.

Dispondo do mundo, a técnica compartimenta, organiza, engessa, emoldura seja comportamentos, realizações pessoais, existências ou acontecimentos vulgares do cotidiano. Em seu último livro Linha $M$, Patti Smith narra como um evento vulgar do cotidiano pode ser devassado pelo alcance tecnológico ao ponto de nos colocar à sua disposição:

Me senti desorientada quando o carro estacionou no Terminal A. Esse é o meu destino?, perguntei. O motorista resmungou alguma coisa e eu desci, tomando cuidado para não esquecer meu gorro preto, e segui para o terminal. O táxi tinha me deixado do lado errado e tive de abrir caminho entre centenas de pessoas indo sei lá para onde para encontrar o guichê de passagens. A garota atrás do balcão insistiu para que eu usasse a máquina. Não sei por onde andei na última década, mas desde quando o conceito de máquina chegou aos terminais aeroviários? [...] tive de revirar minha bolsa para encontrar meus óculos de leitura, e depois de ter respondido a todas as perguntas e escanear meu passaporte, recebi a sugestão de triplicar minhas milhas por 108 dólares. Apertei NÃO e a tela travou. Tive de falar com a garota. Ela me disse para continuar 
apertando o botão. Depois sugeriu que eu tentasse outra máquina [...] o cartão de embarque engasgou e a garota foi obrigada a escarafunchar ali com uma caneta promocional para retirá-lo(SMITH, 2016. p.99).

A resposta automática da funcionária não possibilita improviso. Ela atende às ordens da máquina, este aparelho técnico que realiza funções. Sendo ela mesma uma extensão da máquina, na medida em que suas ações são determinadas a partir do funcionamento dela. Quando a máquina quebra, utiliza-se outra máquina. O improviso não é uma opção de quem recebe ordens, de quem obedece às leis. $\mathrm{O}$ pensamento se ausenta na segurança do que está à mão. Quando nada mais parece funcionar, a funcionária é obrigada a interferir na gestão dos eventos que ficou emperrada, como o bilhete de embarque. Como já aparece em Ser e Tempo, na quebra da manualidade, diante de uma surpresa, os entes aparecem em sua propriedade.

A surpresa proporciona o instrumento num determinado modo de não estar à mão. [...] Na surpresa, importunidade e impertinência, o manual perde, de certo modo, a sua manualidade. No modo de lidar com o que está à mão, porém, sempre se compreende a manualidade, se bem que de maneira não temática. Ela não desaparece mas se despede, por assim dizer, na surpresa do que não pode ser empregado(HEIDEGGER, 2008. p.122-123). 
Embora a funcionária não seja um ente como a máquina que opera, quando seu modo de ser é determinado por esta, ela põe em jogo sua liberdade de ação e de modos de ser. Desse modo ela encerra-se numa possibilidade única antecipada pelo funcionamento encomendado pela dinâmica a que pertence, nesse caso, a da máquina. Portanto, quando a máquina quebra é como se a mulher "funcionária", que obedece a uma função, também quebrasse, permitindo-lhe assim acessar algo de sua propriedade, o improviso, a possibilidade de mudança, um novo modo de ser. $\mathrm{O}$ processo de racionalização que culmina com o desenvolvimento técnico e o advento de novas e sofisticadas tecnologias nos dão a impressão de sermos autônomos no trato e na lida cotidiana com o mundo e as pessoas. A racionalização que faz as engrenagens funcionarem como se fossem autogestoras dá a aparência de organização e sistematização que faz com que a vida e o cotidiano funcionem de forma organizada e segura.

A essa ideia de autogerenciamento da própria vida e das relações sociais, com base no domínio tecnológico da natureza e ampliação das formas de interação humanas, Weber chamou de "desencantamento do mundo". Este era

Simultaneamente, um processo de empobrecimento do sentido e da crítica, pois se fazia acompanhar da crescente sistematização burocrática da vida social, que se impunha a todos com seus procedimentos rotinizados e amparados na obediência e na adequação de cada funcionário ao seu papel no conjunto do sistema (DUARTE, 2010. p.109). 
Na contramão da promessa de organização da vida pelos procedimentos sistemáticos e burocráticos da vida social, acontece um aumento do empobrecimento "do sentido e da crítica”. Ora, se o gerenciamento da vida é ditado pela sua burocratização, o tipo de homens que pode existir aí é o do funcionário, aquele que obedece às regras desse jogo, o que é uma peça da engrenagem.

Numa crítica ao pensamento de Weber, Marcuse afirma que não é apenas no uso que a técnica se mostra como instrumento de dominação, mas em si mesma.

A técnica é dominação sobre a natureza e sobre o homem: uma dominação metódica, científica, calculada e calculadora. Finalidades e interesses determinados da dominação não são introduzidos à técnica apenas 'adicionalmente' e a partir de fora - eles já entram na construção do próprio aparato técnico(HABERMAS, 2014. p.80).

A dominação técnica característica de nossa época não possibilita a afirmação de independência de seu alcance. Nem mesmo o mais longínquo terreno que abriga o camponês mais ignorante da realidade tecnológica está livre do alcance daquela dominação. Isso aparece no seu plantio, por exemplo, seja pelas intercorrências climáticas provocadas pelo aquecimento global, com a queima de combustíveis fósseis, desmatamento, uso de certos fertilizantes, seja pela contaminação de lençóis freáticos pelos agrotóxicos utilizados pelas grandes indústrias 
de alimentos em seu plantio. Para não falar da contaminação do solo por agrotóxicos, transgênicos ou ainda como consequência dos processos de monocultura.

Hoje se perpetua e se amplia a dominação não apenas através da tecnologia, mas como tecnologia fornecendo uma sólida legitimação ao poder político em expansão, o qual abarca em si todas as esferas culturais. Nesse universo, a tecnologia também legitima a ausência de liberdade do homem e comprova sua impossibilidade "técnica" de ser autônomo, de determinar sua própria vida. Pois essa ausência de liberdade não aparece nem como irracional, nem como política, mas sim como a submissão ao aparato técnico que torna a vida mais confortável e o trabalho mais produtivo(HABERMAS, 2014. p.80).

$\mathrm{Na}$ busca de segurança e conforto, ao menos desde o Discurso do Método, buscamos meios de calcular, determinar, aplicar rigor ao nosso pensamento para que ele nos conduza à verdade, à certeza. Esse controle, segundo Descartes, nos possibilitaria andar com segurança pela vida, nos afastaria de erros e equívocos e seria uma promessa de libertação daquilo que nos conduz ao engano, ao erro, como as paixões, os desejos ou a crença dogmática. No entanto, a apologia à racionalidade nos conduz a uma ideia de progresso que culmina na burocratização da vida, na institucionalização das relações sociais e no domínio tecnológico do dia-a-dia ao qual estamos já tão habituados. 
Em todo caso, fazer tremular um ideal de liberdade não é garantia de acesso a ela.

Pois o homem só se torna livre num envio, fazendo-se ouvinte e não escravo do destino.

A essência da liberdade não pertence originariamente à vontade e nem tampouco se reduz à causalidade do querer humano. [...] a liberdade tem seu parentesco mais íntimo com o dar-se do desencobrimento, ou seja, da verdade. [...] Todo desencobrimento provém do que é livre, dirige-se ao que é livre e conduz ao que é livre. A liberdade do livre não está na licença do arbitrário nem na submissão a simples leis. A liberdade é que aclarando encobre e cobre, em cuja clareira tremula o véu que vela o vigor de toda verdade e faz aparecer o véu como véu que vela(HEIDEGGER, 2001. p.28).

Tal como num jogo qualquer, em que o mais importante não é aprender as suas regras, mas aprender o jogo como jogo, e isso é mais importante do que ganhar porque se ajustou às suas regras ou perder porque não as seguiu. O jogo faz parte do destino. Este é um envio histórico de possibilidades. Não é um destino trágico como nos mitos do qual não se pode escapar, nem se esconder. O destino é um horizonte de possibilidades que se apresenta historicamente e que só se realiza quando acontece uma escuta afinada do homem para essas possibilidades que se lhe apresentam e com as quais estabelece uma correspondência. Como num jogo ou numa 
dança em que se espera o movimento e a abertura do outro para que se possa dar o próximo passo. A partir dessa tensão positiva acontece a dança com um par.

Os aparelhos tecnológicos preenchem a vida do homem comum ocupando-lhe a rotina do dia, acrescentam funções à ordem do dia estabelecendo novos comportamentos. Nem Arendt nem Heidegger presenciaram o alcance das tecnologias de comunicação que surgiram com o advento da internet. Porém, podemos ler através do pensamento deles, o vazio do preenchimento que estes aparelhos nos colocam. "Vazio" e "preenchimento", aproximar palavras tão distantes é paradoxal. No entanto a experiência do pensar a que ambos se referem tanto no texto de Arendt Heidegger faz 80 anos, quanto nos textos de Heidegger $O$ que significa pensar $e$ Serenidade a experiência do pensar acontece através daquilo que se ausenta.

Em sua separação essencial em relação ao mundo, o pensar sempre se dedica apenas ao ausente, a questão ou coisas subtraídas à percepção imediata. Se, por exemplo, encontra-se um homem face a face, ele é percebido de fato em sua corporeidade, mas não se pensa nele. Se se pensa, já se interpõe um muro entre os que se encontram, secretamente se distancia o contato imediato. Para se aproximar pelo pensar de uma coisa ou, antes, de um homem, eles devem se manter distantes da percepção imediata. O pensar, diz Heidegger, é 'a aproximação do distante(ARENDT, 1987. p.227). 
Somada ao aparelhamento da vida cotidiana pelos instrumentos tecnológicos está a percepção do tempo e dos acontecimentos que mudam a velocidade da comunicação rápida, por exemplo, nas redes sociais. As notícias pululam de todos os lugares, saltam torrencialmente como chuvas de verão e, como tais, somem no asfalto quente como se não tivesse caído uma gota d'água. A rapidez com que as coisas são noticiadas, uma após a outra, dia-a-dia, hora-a-hora levam nessa mesma velocidade a nossa capacidade de nos espantarmos. Não nos assustamos com a novidade, não nos surpreendemos quando olhamos as "telas" de informação que noticiam novidades a cada minuto. Estando à mão, as novidades são adiadas, o terror é apagado, o choro é deixado para depois. Percebemos esses eventos de modo claro, sobretudo, com a linguagem cibernética, de "memes" a "emoticons" todo riso é suprimido dos lábios. Sendo assim, como afirma Arendt, à esteira de Platão,

“o espanto que é o começo da filosofia - vale para o cotidiano, o evidente, o perfeitamente conhecido e reconhecido; é também a razão de não ser reduzível a nenhum conhecimento" e, acrescenta com Heidegger, do "poder se espantar diante do simples e aceitar esse espanto como morada"(ARENDT, 1987. p.227).

Com a vida organizada, planejada e extremamente aparelhada, o homem comum é bem abrigado em sua moradia, não permite a ausência nem se permite ausentar 
das conveniências que se dispõem ao seu modo de vida, ainda que sistemáticas e burocráticas. Esta, afinal, só é criticada quando não funciona, quando emperra. Quando dá bons resultados, ao contrário, é legítima e recebe aplausos. Confortável com as regras do jogo e cercado por elas não experimenta a ausência que lhe permite pensar. "A superação dessa retirada sempre é paga por uma retirada do mundo dos afazeres humanos, mesmo que o pensar medite justamente esses afazeres em sua calma retirada"(ARENDT, 1987. p. 228).

O distanciamento que permite aproximar-se das coisas na atividade de pensar é prorrogado ou interrompido quando, na ordenação da vida a partir da técnica, tudo já está antecipado e visualizado. A disposição de humor que nos coloca numa sintonia com o mundo é moldada a cada momento pela sensação de autonomia e liberdade que nos é proporcionada pela ideia de que conseguimos acessar tudo, em todo momento, através de aparelhos tecnológicos. Nesse sentido, ao ficarmos sabendo dos fatos do mundo pela internet, imediatamente lemos as críticas disponíveis sobre esses fatos e replicamos essas críticas em nosso discurso, abstendo-nos de pensar, por um momento sequer, sobre aquilo que repetimos. Ausenta-se o pensamento na medida em que se faz presente a repetição e o acúmulo de informações.

No texto Serenidade, Heidegger faz uma distinção entre o pensamento que medita e o pensamento que calcula. Este é o modo de pensar vigente na era técnica, com o qual estamos 
mais habituados. O pensamento que calcula é o que faz a vida "funcionar", o que mede, calcula, organiza, o pensamento presente nas ciências de um modo geral. Segundo ele, o pensamento que calcula é o que nos trouxe à era atômica e com ela a bomba atômica. O pensamento que calcula possibilitou a instauração do mundo técnico, com seus aparelhos e sistemas tal como se apresenta hoje. O pensamento que medita, entretanto, nos coloca diante do mistério "exige de nós que nos ocupemos daquilo que, à primeira vista, parece inconciliável" ou, como afirma Arendt anteriormente, daquilo que é mais distante, do que é ausente. E o que é mais distante do que o próprio mistério? Ater-se ao pensamento do mistério é descobri-lo como tal. Mesmo quando este se apresenta para nós, o máximo que podemos dizer sobre ele é que é um mistério, ou seja, algo que se apresenta como ausente. Quando se aproxima de nós a ponto de definir o nosso modo de vida, a técnica escapa ao nosso pensamento justamente porque se faz presente, não permitindo a questão fundamental a seu respeito, qual seja, a que pergunta pelo seu sentido. Ao mesmo instante, a presença dela é inevitável e por vezes, indispensável.

Façamos a experiência. Para todos nós os equipamentos, aparelhos e máquinas do mundo técnico são hoje imprescindíveis, para uns em maior e para outros em menor grau. Seria insensato investir às cegas contra o mundo técnico. Seria ter vistas curtas querer 
condenar o mundo técnico como uma obra do diabo. Estamos dependentes dos objetos técnicos que até nos desafiam a um sempre crescente aperfeiçoamento. Contudo, sem nos darmos conta, estamos de tal modo apegados aos objetos técnicos que nos tornamos seus escravos(HEIDEGGER, 1959. p.23).

Parece não haver saída diante da realidade que se instaura diante de nós. Por vezes ficamos tentados a pretender um lugar onde não haja o alcance de tanta tecnologia. Um paraíso idílico e inalcançável, dado o alcance da técnica direta ou indiretamente. $\mathrm{O}$ que parece se impor diante desta realidade é uma decisão frente ao uso que fazemos dos aparelhos tecnológicos, ao menos dos que dependem de nosso acesso mais direto. O pensamento que calcula do qual os funcionários da técnica fazem uso não permite a aproximação do mistério, da surpresa ou do espanto. Este modo de pensar lida com o que está dado, com o que já está disposto. Não há novidades nesse modo de pensar. Portanto é um pensamento obediente às normas, aos cálculos, à previsibilidade, às leis. $\mathrm{O}$ pensamento que calcula é o pensamento que usamos quando aprendemos a jogar.

$\mathrm{Na}$ rotina em que nos colocamos diante dessa atividade do pensamento que calcula a paixão, o pathos que possibilita o espanto não se aproxima de um pensar que medita, do pensar apaixonado que se detém diante do vazio que o novo provoca e que o abraça como morada. Um modo de pensar em 
que, como afirma Arendt, "pensar e estar - vivo se tornem um"(ARENDT, 1987. p.225).

Seria possível um modo de se relacionar com a vida, mesmo em seu apresentar-se como instalação burocrática, sistemática e ordeira que nos possibilitasse um caminho em busca de um outro pensar? Que tipo de disposição nos conduziria a este caminho?

Se dissermos "sim" e "não" aos objetos técnicos, não se tornará a nossa relação com o mundo técnico ambígua e incerta? Muito pelo contrário. A nossa relação com o mundo técnico torna-se maravilhosamente simples e tranquila. Deixamos os objetos técnicos entrar no nosso mundo quotidiano e ao mesmo tempo deixamo-los fora, isto é, deixamo-los repousar em si mesmos como coisas que não são algo de absoluto, mas que dependem elas próprias de algo superior. Gostaria de designar esta atitude do sim e do não simultâneos em relação ao mundo técnico com uma palavra antiga: a serenidade para com as coisas(HEIDEGGER, 1959. p. 24).

A serenidade é uma disposição que nos coloca na escuta do mundo, na escuta com o que se revela no mundo, permitindo uma abertura para o novo e desse modo podemos compreender o novo como novo. Nesse sentido, ela permite a meditação do pensamento, uma vez que abre espaço para que se aproxime de nós o mistério. O que, portanto, nos possibilita uma nova relação com o mundo e com as coisas. "A serenidade 
em relação às coisas e a abertura ao mistério dão-nos a perspectiva de um novo enraizamento"(HEIDEGGER,1959. p. 24).

NOTA

${ }^{1}$ Doutoranda em Filosofia pela Universidade Federal de Goiás. E-mail: leidicoimbra@gmail.com. 


\section{REFERÊNCIAS}

ARENDT, Hannah. Eichmann em Jerusalém: um relato sobre a banalidade do mal. São Paulo: Comanhia das Letras,1999.

ARENDT, Hannah. Homens em tempos sombrios. São Paulo: Companhia das Letras, 1987.

DUARTE, A. Vidas em risco: crítica do presente em Heidegger, Arendt e Foucault. Rio de Janeiro: Forense Universitária, 2010.

HABERMAS, Jürgen. Técnica e Ciência como “ideologia”. São Paulo: Editora Unesp, 2014.

HEIDEGGER, Martin. Serenidade. Lisboa: Instituto Piaget, 1959.

HEIDEGGER, Martin. Carta sobre o humanismo. In: Conferências e Escritos Filosóficos. 1984.

HEIDEGGER, Martin. Ser e Tempo. Petrópolis: Vozes, 2008.

HEIDEGGER, Martin. Ensaios e Conferências. Petrópolis: Vozes, 2002.

SMITH, Patti. Linha M. São Paulo: Companhia das Letras, 2016. 